\title{
Produção de alface e acúmulo de nitrato em função da adubação nitrogenada
}

\author{
José Ricardo Mantovani'; Manoel Evaristo Ferreira' ${ }^{1}$; Mara Cristina Pessôa da Cruz ${ }^{1}$ \\ ${ }^{1}$ FCAV-UNESP, Depto. Solos e Adubos, Via de Acesso Prof. Paulo Donato Castellane s/nº 14884-900 Jaboticabal-SP; E-mails: \\ mantovanijr@yahoo.com; evaristo@fcav.unesp.br; mcpcruz@fcav.unesp.br; ${ }^{1}$ Bolsista FAPESP
}

\section{RESUMO}

Conduziu-se um experimento em vasos, em casa de vegetação, visando avaliar o efeito da adubação nitrogenada na produção e no acúmulo de nitrato na parte aérea de cultivares de alface. $\mathrm{O}$ delineamento experimental foi em blocos ao acaso, em esquema fatorial $5 \times 5$, com quatro repetições, utilizando-se 5 doses de nitrogênio: $0 ; 141,5 ; 283 ; 566$ e 1.132 $\mathrm{mg} / \mathrm{vaso}$ de $\mathrm{N}$ como uréia e 5 cultivares de alface: Lucy Brown, Tainá, Vera, Verônica e Elisa. A dose de 283 mg/vaso de N mostrou-se a mais adequada para o cultivo de alface em ambiente protegido, pois o emprego de doses maiores não refletiu em ganho de produção e favoreceu o acúmulo de nitrato na parte aérea das plantas. As cultivares Lucy Brown e Tainá, do grupo americana, acumularam mais nitrato do que as crespas e a lisa.

Palavras-chave: Lactuca sativa, nitrogênio, crescimento.

\begin{abstract}
Lettuce growth and nitrate accumulation in relation to nitrogen fertilization

An experiment using pots under greenhouse conditions was carried out to evaluate the influence of nitrogen fertilization on the growth and nitrate accumulation of lettuce cultivars. The experimental design was of randomized blocks in a $5 \times 5$ factorial scheme, with four replicates. Treatments were five nitrogen rates: 0 ; 141,$5 ; 283 ; 566$ and $1132 \mathrm{mg} / \mathrm{pot} \mathrm{N}$ as urea, and five lettuce cultivars: Lucy Brown, Tainá, Vera, Verônica and Elisa. Maximum growth was observed in the treatment using $283 \mathrm{mg}$ of N/pot. The use of higher rates did not increase plant growth but raised nitrate accumulation in shoot organs. Lucy Brown and Tainá accumulated more nitrate than Vera, Verônica and Elisa cultivars.
\end{abstract}

Keywords: Lactuca sativa, nitrogen, growth.

(Recebido para publicação em 8 de setembro de 2004 e aceito em 4 de abril de 2005)

$\mathrm{A}$ alface (Lactuca sativa L.) é a hortaliça folhosa mais produzida e consumida no Brasil, de baixo valor calórico, sendo boa fonte de vitaminas e de sais minerais (OSHE et al., 2001). Esta espécie apresenta boa resposta à adubação nitrogenada, com efeitos na produção, aumentando o tamanho e melhorando o aspecto das plantas (KATAYAMA, 1993; OSHE, 2000; SANTOS et al., 2001). No cultivo dessa hortaliça, é comum a aplicação de elevadas quantidades de adubo nitrogenado, o que pode propiciar excesso de $\mathrm{N}$, com conseqüente acúmulo de nitrato e diminuição da qualidade do produto (GREENWOOD; HUNT, 1986; FONTES et al., 1997). No estado de São Paulo, a recomendação oficial de adubação nitrogenada para a cultura da alface (TRANI; RAIJ, 1997), em condições de campo, é de 100 a 130 $\mathrm{kg} /$ ha de $\mathrm{N}$, além de 60 a 80 t/ha de esterco de curral, que também é fonte de nitrogênio, contendo em média $13 \mathrm{~g} / \mathrm{kg}$ de $\mathrm{N}$, em base seca.

O acúmulo de nitrato em plantas ocorre quando há desequilíbrio entre a absorção e a assimilação do íon, sendo que as quantidades excedentes são armazenadas nos vacúolos. Dentre as olerícolas, as hortaliças folhosas, como a alface e o espinafre, apresentam maior capacidade de acúmulo de nitrato do que os demais (MAYNARD et al., 1976; BLOM-ZANDSTRA; EENINK, 1986).

A capacidade diferenciada de acúmulo de nitrato não ocorre apenas entre espécies, mas também entre cultivares. Blom-Zandstra e Eenink (1986) verificaram diferenças significativas no acúmulo do íon ao compararem oito genótipos de alface. Além da adubação nitrogenada e do caráter genético, a disponibilidade de Mo, o sistema de cultivo, a intensidade de luz, a temperatura e a umidade do solo, também podem afetar o acúmulo de nitrato nas plantas (MAYNARD et al., 1976; MONDIN, 1996).

Dos fatores ambientais, a intensidade luminosa é o que mais afeta a assimilação de nitrato pelas plantas. Em condições de baixa intensidade luminosa, a atividade da nitrato redutase dimi- nui, ocorrendo acúmulo de nitrato (MAYNARD et al., 1976; RICHARDSON; HARDGRAVE, 1992). Dessa maneira, o teor do íon na planta varia em função do horário de colheita, da época do ano e das condições climáticas. Segundo Mengel e Kirkby (1987), em baixa intensidade luminosa a fotossíntese diminui, afetando a produção de ferridoxina que atua como agente redutor na assimilação do nitrato, e com isso há acúmulo do íon nos vacúolos.

$\mathrm{O}$ nitrato ingerido pelo homem por meio dos alimentos sofre ação microbiana na saliva e é reduzido a nitrito, o qual, por sua vez, reage com aminas e forma compostos $\mathrm{N}$-nitrosos, como as nitrosaminas, que são carcinogênicos. Em crianças, o nitrito pode provocar a metemoglobinemia, processo que leva ao impedimento do transporte de oxigênio dos alvéolos pulmonares para os tecidos, o que pode acarretar a morte (SWANN, 1975; GREENWOOD; HUNT, 1986). Dentre os alimentos, os vegetais são a princi- 
pal fonte de nitrato, contribuindo com cerca de $50 \%$ do total ingerido pelo homem (SCHRÖDER; BERO, 2001).

A preocupação com características de qualidade dos alimentos, entre as quais o teor de nitrato nos vegetais, levou alguns países de clima temperado, onde a preocupação com o teor de nitrato nos alimentos é maior, a fixarem limites aceitáveis. A Comunidade Européia estabeleceu como limites máximos permitidos para alface produzida em ambiente protegido e no campo, teores de $\mathrm{NO}_{3}^{-}$de 3,5 e de $2,5 \mathrm{~g} / \mathrm{kg}$ de matéria fresca, respectivamente (MC CALL; WILLUMSEN, 1998; SCHRÖDER; BERO, 2001). No Brasil, não existe legislação específica que regulamente os teores máximos permitidos de nitrato em vegetais (ZAGO et al., 1999). Além disso, também são escassos no País resultados de pesquisa relacionando a adubação e a qualidade das hortaliças.

O presente trabalho teve como objetivo avaliar o efeito da adubação nitrogenada na produção e no acúmulo de nitrato na parte aérea de cultivares de alface.

\section{MATERIAL E MÉTODOS}

$\mathrm{O}$ experimento foi conduzido em vasos, em casa de vegetação, de maio a agosto de 2000. Utilizou-se amostra da camada arável $(0$ a $20 \mathrm{~cm})$ de um Argissolo Vermelho-Amarelo distrófico, coletado em uma área de pastagem, com a seguinte caracterização química e granulométrica: $\mathrm{P}$ resina $=8 \mathrm{mg} / \mathrm{dm}^{3}$; M.O. $=37 \mathrm{~g} / \mathrm{dm}^{3} ; \mathrm{pH}$ em $\mathrm{CaCl}_{2} 0,01$ $\mathrm{mol} / \mathrm{L}=4,8 ; \mathrm{K}^{+}, \mathrm{Ca}^{2+}, \mathrm{Mg}^{2+}, \mathrm{H}+\mathrm{Al}, \mathrm{SB}$ e CTC, respectivamente, iguais a 2,1 ; $22 ; 10 ; 38 ; 34$ e $72 \mathrm{mmol} / \mathrm{dm}^{3} ; \mathrm{V}=47 \%$; argila $=160 \mathrm{~g} / \mathrm{kg}$, e areia $=770 \mathrm{~g} / \mathrm{kg}$. No solo, também foram feitas análises de $\mathrm{S}_{-} \mathrm{SO}_{4}{ }^{2-}$, de $\mathrm{B}$ e de $\mathrm{Cu}, \mathrm{Fe}, \mathrm{Mn}$ e $\mathrm{Zn}$, cujos resultados foram, respectivamente, iguais a $4 ; 0,27 ; 1,4 ; 79 ; 13,8$ e 3,1 $\mathrm{mg} / \mathrm{dm}^{3}$.

Empregou-se o delineamento em blocos ao acaso, em esquema fatorial, combinando 5 doses de $\mathrm{N}$ e 5 cultivares de alface, com quatro repetições. As doses de nitrogênio foram $0 ; 141,5 ; 283$; 566 e $1.132 \mathrm{mg} /$ vaso de $\mathrm{N}$, utilizando como fonte a uréia, correspondentes, com base na superfície do vaso $(471,4$ $\mathrm{cm}^{2}$ ), a, aproximadamente, $0 ; 30 ; 60$; 120 e $240 \mathrm{~kg} / \mathrm{ha}$ de N. As cultivares de alface foram Lucy Brown e Tainá (grupo americana), Vera e Verônica (grupo solta-crespa) e Elisa (repolhuda-lisa).

Volumes de $5,5 \mathrm{dm}^{3}$ de solo receberam $\mathrm{CaCO}_{3}$ e $4 \mathrm{MgCO}_{3} \cdot \mathrm{Mg}(\mathrm{OH})_{2} \cdot 5 \mathrm{H}_{2} \mathrm{O}$, na proporção $\mathrm{Ca}: \mathrm{Mg}$ de 4:1, para elevar a saturação por bases do solo a $80 \%$, e $82,5 \mathrm{~g}$ de composto de lixo urbano, equivalentes, com base no volume de solo empregado, a 30 t/ha. O composto de lixo foi analisado conforme descrito em Kiehl (1985), e apresentou $150 \mathrm{~g} / \mathrm{kg}$ de umidade, $\mathrm{pH}$ em $\mathrm{CaCl}_{2}=7,4 \mathrm{e}$, na base seca: $\mathrm{C}=157 \mathrm{~g} / \mathrm{kg} ; \mathrm{N}=14 \mathrm{~g} / \mathrm{kg}$; relação $\mathrm{C} / \mathrm{N}=11 / 1$; P, K, Ca e Mg, respectivamente, iguais a $4 ; 2 ; 25$ e $4 \mathrm{~g} / \mathrm{kg}$; $\mathrm{Cu}, \mathrm{Fe}, \mathrm{Mn}$ e $\mathrm{Zn}$, respectivamente, iguais a $181 ; 26.852 ; 412$ e $544 \mathrm{mg} / \mathrm{kg}$. Portanto, com a aplicação do composto de lixo foram fornecidos $981 \mathrm{mg} / \mathrm{vaso}$ de N-orgânico.

As porções de solo tratadas com os insumos (carbonatos e composto de lixo urbano) foram transferidas para vasos de alumínio com capacidade para 5,8 L, umedecidas com água desionizada a $60 \%$ da capacidade de retenção e submetidas a incubação por 30 dias. Aos 22 dias de incubação, foi feita adubação mineral em todas as parcelas, tendo sido adicionados, em mg/vaso: 550 de P; 960 de K; 110 de S e 2,75 de B. Para tanto, foi usada solução preparada a partir de $\mathrm{KH}_{2} \mathrm{PO}_{4}, \mathrm{~K}_{2} \mathrm{SO}_{4}$ e $\mathrm{H}_{3} \mathrm{BO}_{3}$.

Ao término da incubação, o solo foi seco ao ar e amostrado para análise química de rotina. Após a amostragem, volumes de $5 \mathrm{dm}^{3}$ de solo foram devolvidos para os vasos, reumedecidos a $60 \%$ da capacidade de retenção de água, e cada vaso recebeu uma muda de alface, preparada em bandejas de isopor de 200 células. A adubação nitrogenada foi feita por meio de solução, sendo parcelada em quatro vezes, aos 20 dias de incubação e aos 10; 20 e 30 dias após o transplantio das mudas de alface, sendo que cada aplicação forneceu, respectivamente, $30 \% ; 20 \% ; 20 \%$ e $30 \%$ das doses empregadas. Aos 32 dias após o transplantio, foi feita adubação potássica de cobertura, tendo sido adicionados 375 $\mathrm{mg} /$ vaso de K, por meio de solução preparada a partir de $\mathrm{K}_{2} \mathrm{SO}_{4}$ e $\mathrm{KCl}$.
A colheita foi iniciada 45 dias após o transplantio das mudas, com uma repetição por dia, em todas as cultivares. Sistematizou-se o horário de colheita das $6 \mathrm{~h} 30 \mathrm{~min}$ às $7 \mathrm{~h} 30 \mathrm{~min}$, pois, de acordo com Maynard et al. (1976), entre os fatores que influenciam no acúmulo de nitrato em plantas, estão a intensidade luminosa e a temperatura. As plantas foram cortadas rente à superfície do solo de cada vaso, pesadas para obtenção da produção de matéria fresca e, rapidamente, colocadas em sacos de plástico e mantidas em geladeira a $4^{\circ} \mathrm{C}$, até serem lavadas conforme recomendação de Bataglia et al. (1983). Em seguida, as plantas foram secadas em estufa com circulação forçada de ar em torno de $65^{\circ} \mathrm{C}$, até atingirem peso constante, depois foram moídas em moinho do tipo Willey e subamostras foram trituradas em almofariz para passar em peneira de $0,355 \mathrm{~mm}$ (42 mesh) de abertura de malha.

$\mathrm{Na}$ matéria seca das plantas, foi feita determinação de $\mathrm{N}$-orgânico+N-NH${ }_{4}^{+}$ (NOA), por meio de digestão sulfúrica, destilação dos extratos em microdestilador Kjeldahl e subseqüente titulação do destilado (SARRUGE; HAAG, 1974), e de nitrato, por meio de extração do íon com água desionizada, passagem dos extratos em coluna de cádmio esponjoso para a redução do nitrato a nitrito e quantificação colorimétrica do nitrito (FOLLETT; RATCLIFF, 1963). Os resultados obtidos foram convertidos em teores e quantidades acumuladas de NOA e de nitrato $\left(\mathrm{NO}_{3}^{-}\right)$na parte aérea das plantas e submetidos à análise de variância.

\section{RESULTADOS E DISCUSSÃO}

Verificou-se efeito quadrático da adubação nitrogenada na produção de matéria fresca da parte aérea das cinco cultivares (Figura 1). Estimou-se, pelas equações, uma produção máxima por cultivar de 620; 608; 531; 533 e 467 g/ planta, obtida com a aplicação de 710 ; 642; 770; 830 e 898 mg/vaso de N, correspondentes a, aproximadamente, 151; 136; 163; 176 e $190 \mathrm{~kg} / \mathrm{ha}$ de N, para Lucy Brown, Tainá, Vera, Verônica e Elisa, respectivamente. Em experimento de campo, Hemphill Jr. e Jackson 
(1982) obtiveram resposta linear da matéria fresca de alface à aplicação de $\mathrm{N}$ $\left(\mathrm{NH}_{4} \mathrm{NO}_{3}\right)$, até a dose de $168 \mathrm{~kg} / \mathrm{ha}$ de $\mathrm{N}$, para valores de $\mathrm{pH}$ do solo acima de 6 .

Os teores de $\mathrm{N}$-orgânico+N-NH${ }_{4}^{+}$ (NOA) na parte aérea das cultivares aumentaram com as doses de nitrogênio, variando de 18,2 a 30,5 na cv. Lucy Brown; 19,3 a 31,5 na cv. Tainá; 17,9 a 35,8 na cv. Vera; 17,5 a 32,9 na $\mathrm{cv}$. Verônica, e de 16,8 a $32,5 \mathrm{~g} / \mathrm{kg}$ na cv. Elisa. Teores de $\mathrm{N}$ entre 30 e $50 \mathrm{~g} / \mathrm{kg}$ são considerados adequados para alface (TRANI; RAIJ, 1997). Dessa maneira, os teores estiveram dentro dos limites citados apenas no tratamento que recebeu a maior dose de N. Entretanto, deve-se salientar que a parte e a idade da planta analisadas por Trani e Raij (1997) foram folhas de alface recémdesenvolvidas e coletadas na metade do ciclo, diferindo das empregadas nesse experimento, em que se utilizou toda a parte aérea no final do ciclo.

Fontes et al. (1997) determinaram o teor de $37,5 \mathrm{~g} / \mathrm{kg}$ de $\mathrm{N}$ na matéria seca como nível crítico para alface Brasil 202, colhida aos 45 dias após o transplantio. Os teores de NOA obtidos nesse experimento foram menores do que o nível crítico citado. Contudo, além de terem sido utilizadas cultivares diferentes, as produções médias de matéria seca do atual experimento foram cerca de $50 \%$ maiores do que a produção máxima observada pelos autores. É possível, portanto, que os teores obtidos estejam refletindo um efeito de diluição no decorrer do ciclo de desenvolvimento da cultura.

Verificou-se que as quantidades acumuladas de NOA na matéria seca da parte aérea das cinco cultivares de alface aumentaram com a adubação nitrogenada, até a dose estimada de 900 na cv. Lucy Brown; 936 na cv. Tainá; 1.142 na cv. Vera; 991 na cv. Verônica e 962 mg/vaso na cv. Elisa (Figura 2).

Os teores de $\mathrm{NO}_{3}{ }^{-}$na matéria seca da parte aérea das cinco cultivares de alface aumentaram linearmente com as doses de nitrogênio, variando de 2,87 a 34,14 na cv. Lucy Brown; 5,62 a 42,62 na cv. Tainá; 1,40 a 34,82 na cv. Vera; 1,50 a 29,89 na cv. Verônica, e 1,29 a $21,47 \mathrm{~g} / \mathrm{kg}$ na cv. Elisa (Figura 3). Com base no teor de água das plantas, os teo-

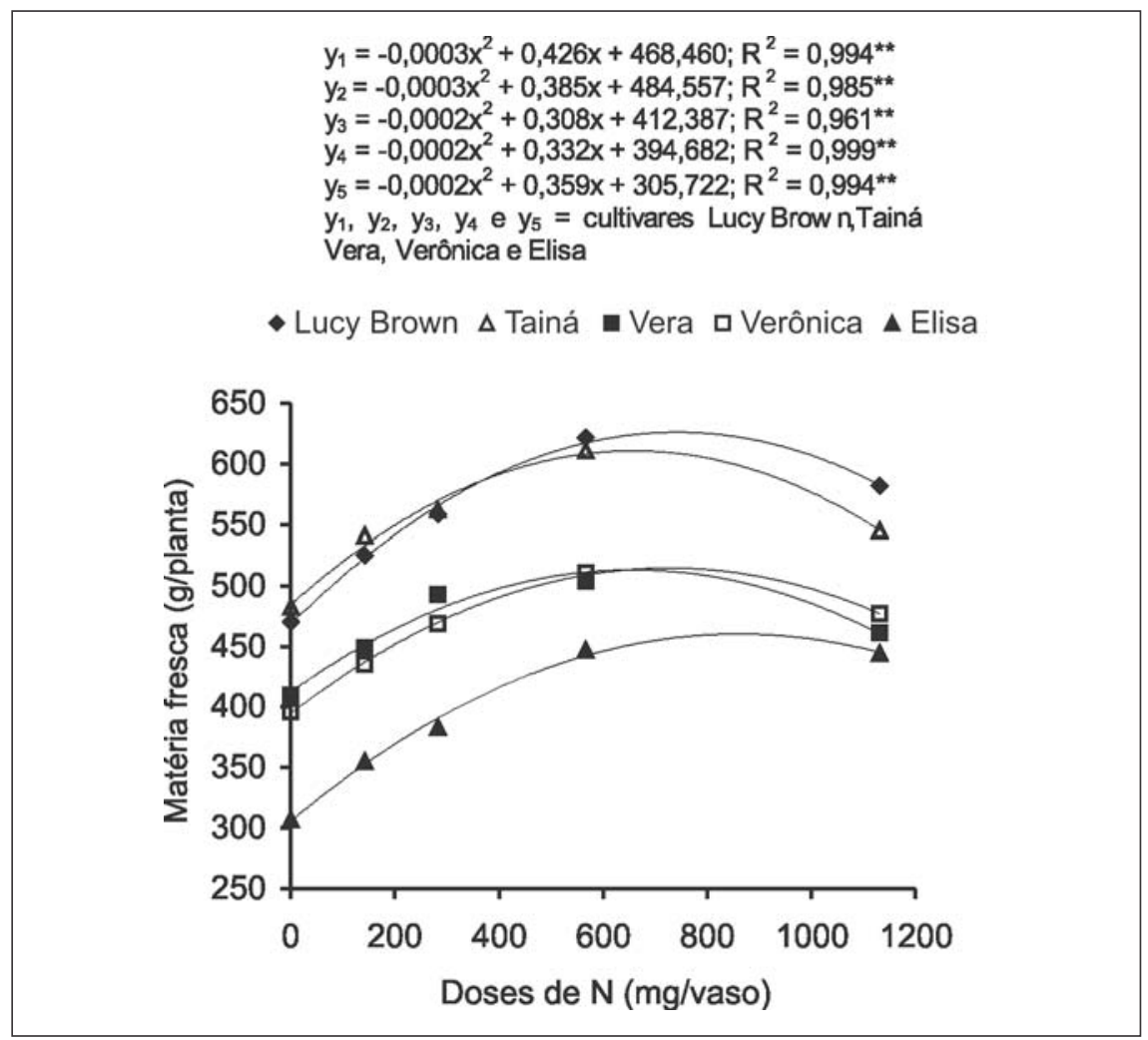

Figura 1. Produção de matéria fresca da parte aérea das cultivares de alface, em função de adubação nitrogenada. Jaboticabal, UNESP, 2000.

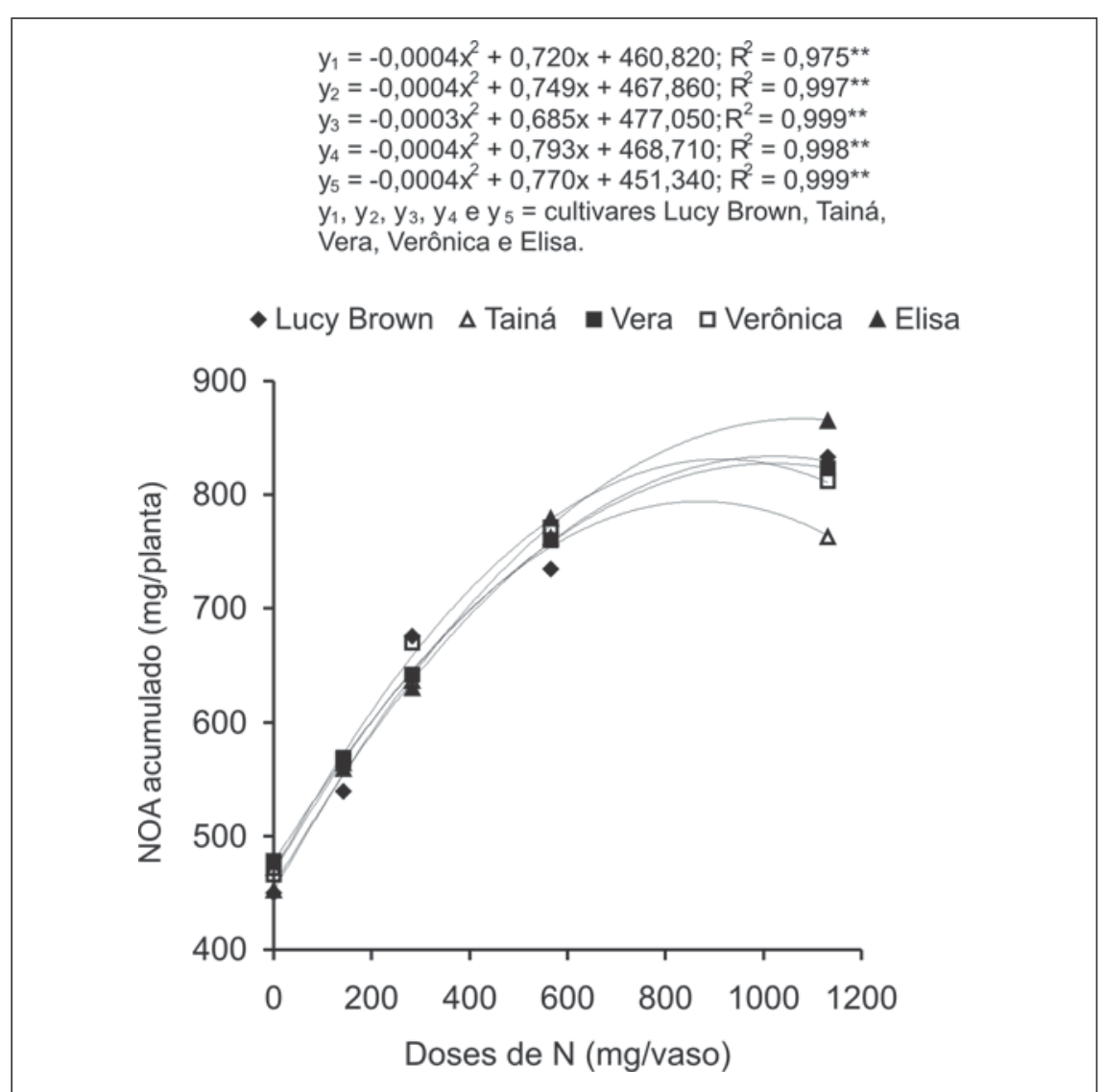

Figura 2. Quantidades acumuladas de $\mathrm{N}$-orgânico $+\mathrm{N}^{-\mathrm{NH}_{4}+}(\mathrm{NOA})$ na matéria seca da parte aérea das cultivares de alface, em função de adubação nitrogenada. Jaboticabal, UNESP, 2000. 


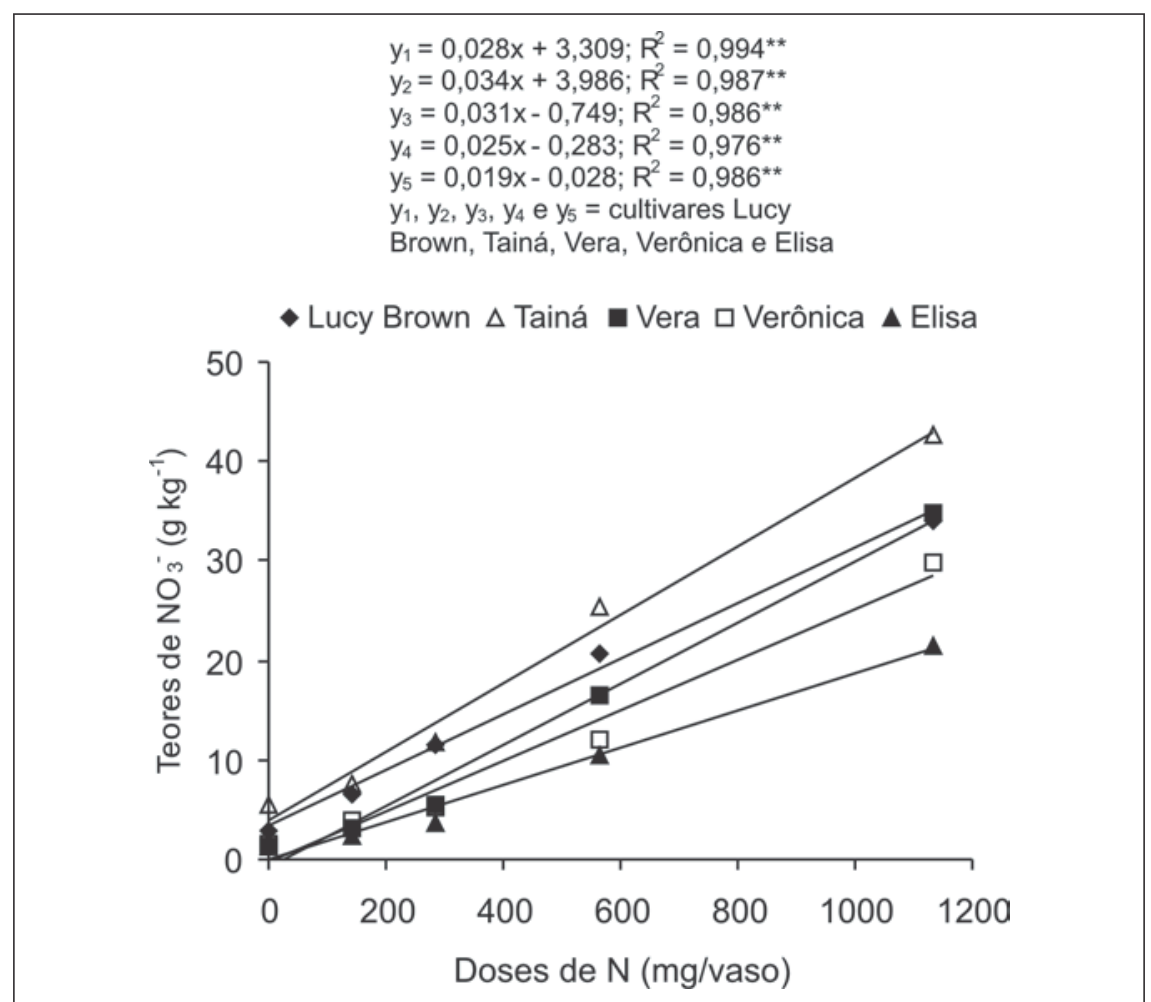

Figura 3. Teores de $\mathrm{NO}_{3}^{-}$na matéria seca da parte aérea das cultivares de alface, em função de adubação nitrogenada. Jaboticabal, UNESP, 2000.

res de $\mathrm{NO}_{3}^{-}$na matéria seca foram convertidos para matéria fresca, obtendose a seguinte variação: 0,16 a 1,60 na cv. Lucy Brown; 0,29 a 1,91 na cv. Tainá; 0,09 a 1,37 na cv. Vera; 0,10 a 1,54 na cv. Verônica, e 0,12 a $1,29 \mathrm{~g} / \mathrm{kg}$ na cv. Elisa. Esses valores ficaram abaixo dos limites máximos toleráveis estabelecidos pela Comunidade Européia, que são 2,50 e 3,50 g/kg de matéria fresca, para o cultivo de alface no campo, e em ambiente protegido, respectivamente (MCCALL; WILLUMSEN, 1998; SCHRÖDER; BERO, 2001). As plantas que receberam a maior dose de $\mathrm{N}$ apresentaram teores de $\mathrm{NO}_{3}^{-}$que, dependendo da cultivar, foram 45 a $63 \%$ menores que o limite máximo admissível para o cultivo em ambiente protegido. Se para cada cultivar fosse empregada a dose de $\mathrm{N}$ necessária para atingir a produção máxima, os teores estimados de $\mathrm{NO}_{3}^{-}$na matéria fresca das plantas seriam, em média, $69 \%$ menores que o limite admissível de 3,50 g/kg de matéria fresca.

De acordo com a Organização Mundial da Saúde, a ingestão diária aceitável de $\mathrm{NO}_{3}^{-}$é de, no máximo, 3,65 mg/ aérea das cultivares (Figura 4). Verificou-se também, por meio do teste de Tukey, que as cultivares Lucy Brown e Tainá (ambas do grupo americana) apresentaram maior acúmulo do íon que as demais (dms para cultivares $=86 \mathrm{mg}$ ) . Resultados semelhantes foram obtidos por Mondin (1996), que verificou maior acúmulo de nitrato pelas cultivares Lucy Brown e Tainá (grupo americana) em relação à Verônica (grupo crespa), em cultivo orgânico e organomineral.

Comparando os dados de produção de matéria fresca (Figura 1) com os das quantidades acumuladas de $\mathrm{NO}_{3}{ }_{3}^{-}$na parte aérea das plantas (Figura 4), verificou-se, para todas as cultivares, que, com o aumento das doses de $\mathrm{N}$, houve maior acúmulo de $\mathrm{NO}_{3}^{-}$do que acréscimo de matéria fresca, de tal maneira que a maior dose de $\mathrm{N}$ propiciou maior perda de qualidade das plantas do que ganho em produção. Segundo McCall e Willumsen (1998), a dose de N recomendada para alface deve aliar a máxima produção ao menor acúmulo de nitrato. Assim, a dose de $\mathrm{N}$ a ser aplicada para a obtenção para cada cultivar da produção máxima, proporcionaria, de acordo com as equações de regressão da Figura 4, as seguintes quantidades acumuladas de $\mathrm{NO}_{3}^{-}$na parte aérea das plantas: 620; 655; 539; 529 e 451 mg/planta, para as cultivares Lucy Brown, Tainá, Vera, Verônica e Elisa, respectivamente. Em contrapartida, a dose de $\mathrm{N}$ de 283 $\mathrm{mg} /$ vaso, correspondente a, aproximadamente, $60 \mathrm{~kg} / \mathrm{ha}$, propiciou, em média, $90 \%$ da produção máxima e acúmulo de $\mathrm{NO}_{3}{ }_{3}^{-}$na parte aérea das plantas de 297; 350; 202; 190 e 144 mg/planta, valores $60 \%$ menores, em média, do que as quantidades anteriormente mencionadas. Portanto, os aumentos de produção obtidos com o emprego de doses de $\mathrm{N}$ acima de $283 \mathrm{mg} /$ vaso foram relativamente pequenos enquanto que o acúmulo de $\mathrm{NO}_{3}^{-}$aumentou em maior proporção. A dose de $283 \mathrm{mg} / \mathrm{vaso}$, correspondente a, aproximadamente, $60 \mathrm{~kg} /$ ha, é metade da recomendada por Trani e Raij (1997) para o cultivo de alface; entretanto, os resultados foram obtidos em uma condição em que não houve perdas de nitrogênio por lixiviação, o que não ocorre no campo, devido à grande mobilidade (lixiviação) do nutriente. 


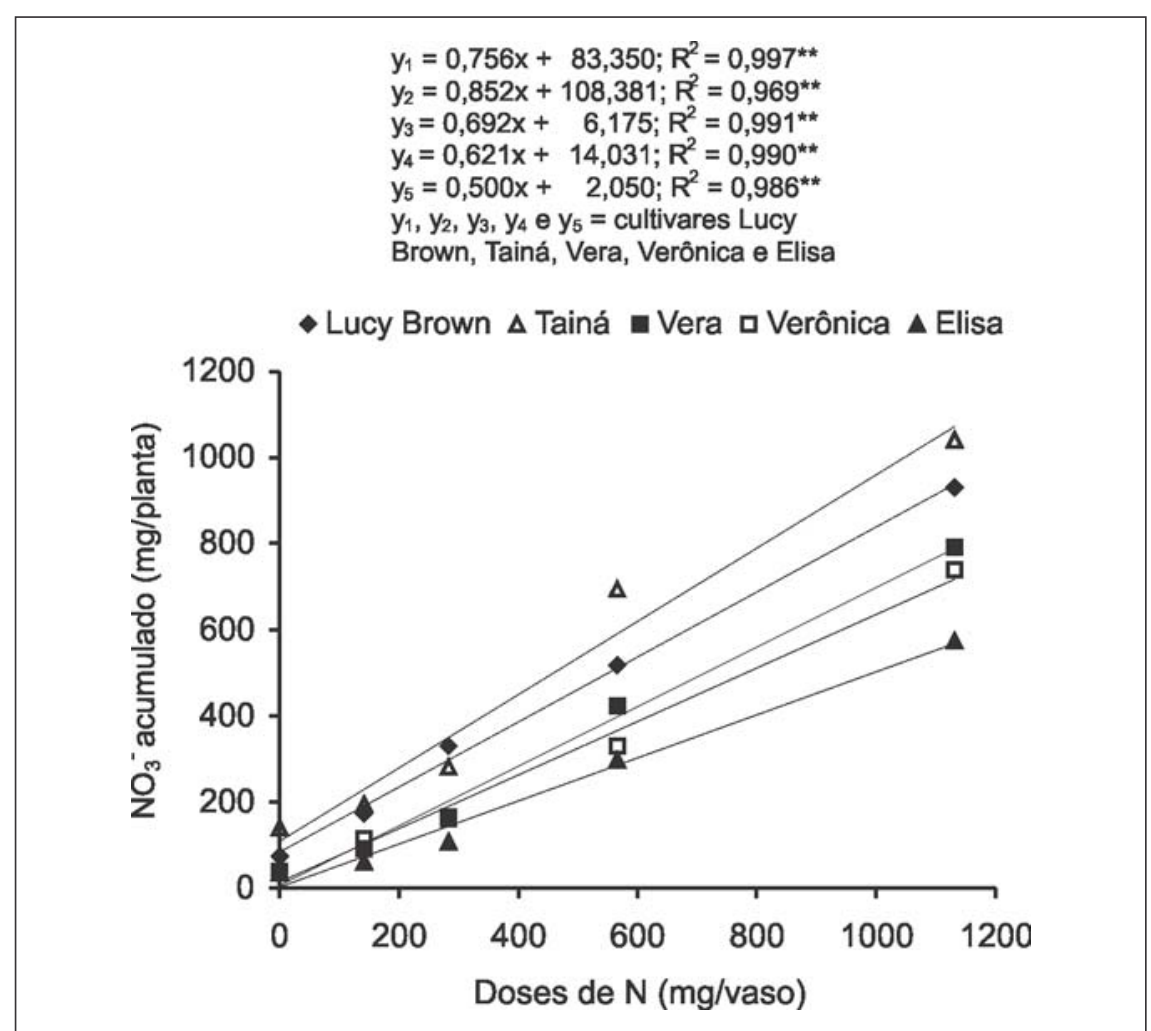

Figura 4. Quantidades acumuladas de $\mathrm{NO}_{3}^{-}$na matéria seca da parte aérea das cultivares de alface, em função de adubação nitrogenada. Jaboticabal, UNESP, 2000.

De acordo com os resultados obtidos, infere-se que a dose de $283 \mathrm{mg} /$ vaso de $\mathrm{N}$, correspondente a, aproximadamente, $60 \mathrm{~kg} / \mathrm{ha}$ de $\mathrm{N}$, é a mais adequada para o cultivo de alface em ambiente protegido, pois doses maiores não refletem em ganho de produção e favorecem o acúmulo de nitrato na parte aérea. As cultivares Lucy Brown e Tainá, do grupo americana, acumulam mais nitrato do que as crespas e a lisa.

\section{LITERATURA CITADA}

BATAGLIA, O.C.; FURLANI, A.M.C.; TEIXEIRA, J.P.F.; FURLANI, P.R.; GALLO, J.R Métodos de análise química de plantas. Campinas: Instituto Agronômico, 1983. 48 p. (Boletim Técnico, 78).

BLOM-ZANDSTRA, M.; EENINK, A.H. Nitrate concentration and reduction in different genotypes of lettuce. Journal of the American Society for Horticultural Science, v.111, n.6, p.908-911, 1986.
FOLLETT, M.J.; RATCLIFF, P.W. Determination of nitrite and nitrate in meat products. Journal of the Science of Food and Agriculture, v.14, n.2, p.138-144, 1963.

FONTES, P.C.R.; PEREIRA, P.R.G.; CONDE, R.M. Critical chlorophyll, total nitrogen, and nitrate-nitrogen in leaves associated to maximum lettuce yield. Journal of Plant Nutrition, v.20, n.9, p.1061-1068, 1997.

GREENWOOD, D.J.; HUNT, J. Effect of nitrogen fertilizer on the nitrate contents of field vegetables grown in Britain. Journal of the Science of Food and Agriculture, v.37, n.4, p.373-383, 1986.

HEMPHILL Jr., D.D.; JACKSON, T.L. Effect of soil acidity and nitrogen on yield and elemental concentration of bush bean, carrot, and lettuce. Journal of the American Society for Horticultural Science, v.107, n.5, p.740-744, 1982.

KATAYAMA, M. Nutrição e adubação de alface, chicória e almeirão. In: FERREIRA, M.E.; CASTELLANE, P.D.; CRUZ, M.C.P. (Ed.) $\mathrm{Nu}$ trição e adubação de hortaliças. Piracicaba: POTAFOS, 1993. cap. 4, p.141-148.

KIEHL, E.J. Fertilizantes orgânicos. São Paulo: Agronômica Ceres, 1985. 492 p.
MATTOS, L.L.; MARTINS, I.S. Consumo de fibras alimentares em população adulta. Revista de Saúde Pública, v.34, n.1, p.50-55, 2000.

MAYNARD, D.N.; BARKER, A.V.; MINOTTI, P.L.; PECK, N.H. Nitrate accumulation in vegetables. Advances in Agronomy, v.28, p.71-118, 1976.

MENGEL, K.; KIRKBY, E.A. Principles of plant nutrition. 4 ed. Bern: International Potash Institute, 1987. $687 \mathrm{p}$

McCALL, D.; WILLUMSEN, J. Effects of nitrate, ammonium and chloride application on the yield and nitrate content of soil-grown lettuce. Journal of Horticultural Science \& Biotechnology, v.73, n.5, p.698-703, 1998.

MONDIN, M. Efeito de sistemas de cultivo na produtividade e acúmulo de nitrato em cultivares de alface. 1996. $88 \mathrm{f}$. (Tese doutorado), FCAV, UNESP, Jaboticabal.

OHSE, S. Qualidade nutricional e acúmulo de nitrato em alface. In: SANTOS, O.S. (Ed.) Hidroponia da alface. Santa Maria: Imprensa Universitária, 2000. cap. 2, p.10-24.

OSHE, S.; DOURADO-NETO, D.; MANFRON, P.A.; SANTOS, O.S. Qualidade de cultivares de alface produzidos em hidroponia. Scientia Agricola, v.58, n.1, p.181-185, 2001.

RICHARDSON, S.J.; HARDGRAVE, M. Effect of temperature, carbon dioxide enrichment, nitrogen form and rate of nitrogen fertilizer on the yield and nitrate content of two varieties of glasshouse lettuce. Journal of the Science of Food and Agriculture, v.59, p.345-349, 1992.

SANTOS, R.H.S.; SILVA, F.; CASALI, V.W.D.; CONDE, A.R. Efeito residual da adubação com composto orgânico sobre o crescimento e produção de alface. Pesquisa Agropecuária Brasileira, Brasília, v.36, n.11, p.1395-1398, 2001.

SARRUGE, J.R.; HAAG, H.P. Análises químicas em plantas. Piracicaba: ESALQ, 1974. 56 p.

SCHRÖDER, F.G.; BERO, H. Nitrate uptake of Lactuca sativa $\mathrm{L}$. depending on varieties and nutrient solution in hydroponic system PPH. Acta Horticulturae, n.548, p.551-555, 2001.

SWANN, P.F. The toxicology of nitrate, nitrite and $\mathrm{N}$-nitroso compounds. Journal of the Science of Food and Agriculture, v.26, n.11, p.1761-1770, 1975.

TRANI, P.E.; RAIJ, B. Hortaliças. In: RAIJ, B.; CANTARELLA, H.; QUAGGIO, J.A.; FURLANI, A.M.C.(Ed.). Recomendações de adubação e calagem para o Estado de São Paulo. 2.ed.rev.atual. Campinas: Instituto Agronômico/ Fundação IAC, 1997. cap.18, p.157-185. (Boletim Técnico, 100)

ZAGO, V.C.P.; EVANGELISTA, M.R.; ALMEIDA, D.L.; GUERRA, J.G.M.; PRATA, M.C.P.; RUMJANEK, N.G. Aplicação de esterco bovino e uréia na couve e seus reflexos nos teores de nitrato e na qualidade. Horticultura Brasileira, Brasília, v. 17, n. 3, p. 207-211, 1999. 